\title{
The Role of New Technology in Advancing Ocean Biogeochemical Research
}

\author{
Tommy D. Dickey \\ University of California . Santa Barbara, California USA
}

\section{Introduction}

The rapid increase in atmospheric carbon dioxide $\left(\mathrm{CO}_{2}\right)$ levels has stimulated a growing interest in understanding biogeochemical processes in the ocean and their interactions with the atmosphere. Interestingly, surface $\mathrm{CO}_{2}$ is also reported to be rising at the Joint Global Ocean Flux Study (JGOFS) ocean time series sites off Hawaii and Bermuda. Potential effects of rising $\mathrm{CO}_{2}$ levels include increases in global atmospheric and oceanic temperatures, melting of ice caps, sea-level rise and shifts in regional weather patterns, that lead to droughts and floods. One important question concerns our ability to discern natural versus anthropogenic contributions to this rise. Another question concerns the role the ocean plays in the cycling and variability of $\mathrm{CO}_{2}$. These and other unanswered questions stimulated the development and execution of JGOFS, a multidisciplinary and international program carried out between 1987 and 2001 by more than 20 nations. JGOFS was designed to study oceanic biogeochemical cycles and their interaction with a changing climate.

On millennial time scales, the ocean dictates the atmospheric concentration of $\mathrm{CO}_{2}$. There is an inverse gradient in Dissolved Inorganic Carbon (DIC) in the ocean, such that higher concentrations of DIC are found at greater depths. In contrast, the upper portion of the water column is in overall equilibrium with the atmosphere to first order. This gradient is maintained by two carbon "pumps." The "solubility pump" depends on the fact that cold water holds more $\mathrm{CO}_{2}$ than warm water; for example, the solubility of cold, deep water is about twice as great as that of near-surface equatorial water. As a consequence, the net effect of sinking surface waters through thermohaline circulation is to enrich deeper waters in carbon.

The second carbon pump is known as the "biological pump", and is the primary focus of this review of new technologies and observations (see Ducklow et al., this issue). The biological pump's process begins with phytoplankton living in the upper or euphotic layer of the ocean. Phytoplankton take up $\mathrm{CO}_{2}$ and nutrients to form organic matter. Although much of this organic matter is metabolized and recycled in the surface waters, a significant portion (roughly $10 \%$ to $20 \%$ but varying greatly over space and time) sinks into the deep ocean before it is remineralized into an inorganic form via the metabolism of microorganisms. Currents and upwelling return $\mathrm{CO}_{2}$ to the surface of the ocean, but the overall effect of the biological pump is to transport carbon into the deep ocean.

The solubility and biological pumps have significant effects on atmospheric $\mathrm{CO}_{2}$ levels. The biological pump includes pathways of carbon export to the deeper layers through Dissolved Organic Carbon (DOC) molecules (see Hansell and Carlson, this issue) and Particulate Organic Carbon (POC) matter (see Berelson, this issue). The determination of primary production in the upper ocean is a vital step in quantifying the formation of POC, which is then available for transport via the biological pump. The following paragraphs introduce some of the key concepts regarding primary production in relation to the biological pump, with a focus on its quantification using autonomous measurements from moorings and other platforms.

The biological pump is of interest to researchers studying bio-optics and upper-ocean physics as well as biogeochemistry. Primary productivity and phytoplankton biomass depend on photosynthetic processes, which implicitly involve the availability of light (measured as Photosynthetically Available Radiation or [PAR]) and nutrients such as nitrate, silicate, phosphate, and iron. The spectral quality and intensity of light varies with depth and is important for specific phytoplankton species with special pigmentation or photoadaptive characteristics. Light exposure for individual organisms is affected by variation in physical conditions including mixed layer depth, turbulence and currents, as well as the incident solar radiation, all of which vary in time and space. An important feedback concerns the modulation of the spectral light field 
at various depths as phytoplankton concentrations and communities wax and wane. Fundamental measurements and models have been used to estimate primary production (e.g., Behrenfeld and Falkowski, 1997). Such models often use measurements of chlorophyll $a$ concentrations and PAR.

Primary production has been estimated for a variety of geographical regions using remote sensing via instruments mounted on satellites. Primary production, $P(z)$, as a function of depth, $z$, has also been estimated with relatively simple models using chlorophyll $a, \operatorname{Chl}(\mathrm{z})$, and $\operatorname{PAR}(\mathrm{z})$ data. In some cases, best estimates or measurements of the chlorophyll a specific light absorption coefficient for phytoplankton, $\mathrm{a}^{*}(\mathrm{z})$, and the quantum yield for carbon fixation, $\Phi(z)$, have been utilized as in the following empirical formulation:

$$
P(z)=a^{*}(z) \Phi(z) \operatorname{Chl}(z) \operatorname{PAR}(z)
$$

One of the deficiencies of this method is that neither $\mathrm{a}^{*}$ nor $\Phi$ is constant in space or time because of changes in community structure and varying light and nutrient stresses.

This review focuses on some of the technological and observational advances achieved primarily during the JGOFS era that are improving our understanding of biogeochemical processes, pools and fluxes in the ocean. It is not comprehensive, but rather highlights a few examples (more references are available at http://www.opl.ucsb.edu/). The focus is on in situ observations, with a few references to complementary remote sensing data (see Yoder et al., this issue).

\section{The Sampling Problem}

Oceanographers must obtain their data from an uncontrolled and often harsh environment. The limits of detection, precision and accuracy of ocean measurements should not be overlooked. It is critically important to obtain large volumes of data because of the vastness and complexity of the ocean and the importance of a large range of time and space scales (Figure 1a) for answering many basic questions. The oceans are naturally dynamic, with large-amplitude periodic and episodic variability that confounds attempts to quantify long-term trends and changes. Recent studies suggest that a few powerful episodic events can often be of far greater importance than small-amplitude, slower variations. JGOFS has characterized, quantified and improved our understanding of ocean processes that affect variability in carbon inventories and carbon fluxes. But insufficient data and undersampling still limit our ability to make further advances in understanding and modeling the biogeochemistry of the ocean. We must find ways to increase massively the variety and quantity of biogeochemical data.

Studies of ocean biogeochemistry necessarily rely heavily on interdisciplinary data sets because of the interdependence of physical, chemical, biological and geological processes. Ideally, the relevant data should be collected simultaneously and span broad time and space scales to observe processes of interest (Figure 1a). For global climate problems, this means sampling variability that extends over 10 orders of magnitude in space, and even longer in time. Present capabilities for obtaining the necessary atmospheric and physical oceanographic data are relatively well advanced in contrast to those for biogeochemical data. This is not surprising, considering the greater complexity and non-conservative nature of the chemistry and biology of the ocean. Nonetheless, remarkable advances in biogeochemical data collection are being made. New platforms are making it possible to measure certain biogeochemical, bio-optical, chemical and geological parameters on the same time and space scales as physical ones (Figure 1b). Figure 2 shows some examples of data collection platforms, such as moorings, towed vehicles (e.g. SeaSoar), drifters, floats, gliders, and Autonomous Underwater Vehicles (AUVs) now in operation.

\section{Emerging Observational Methods and Results}

One of the central goals of JGOFS has been to measure and understand time-varying fluxes of carbon and associated biogenic elements. Regional studies are necessary to sample processes and to develop models for strategic oceanic biomes. All regions experience certain small- and mesoscale processes, especially over short time periods. But the effects of natural phenomena such as monsoons, equatorial longwaves, spring blooms, hurricanes and typhoons, deep convection, El Niño-Southern Oscillation, climatic oscillations and the like vary greatly from one region to another. This section presents examples of applications of new technologies in various regions studied by JGOFS, and provides some highlight results.

\section{JGOFS In The Arabian Sea}

The U.S. JGOFS process studies were conducted in the Arabian Sea between 1994 and 1996 (Deep-Sea Research II, vols. 45[10-11], 46[3-4, 8-9], 47[7-8]). Before JGOFS, we did not know whether the Arabian Sea absorbs or releases $\mathrm{CO}_{2}$ into the atmosphere on balance, and upper-ocean physical and biogeochemical responses to monsoonal forcing were undocumented. Arabian Sea field studies employed 1) underway shipboard sampling with Acoustic Doppler Current Profilers (ADCPs) and other instruments, 2) towed instrument systems such as SeaSoar, 3) multiple moorings, and 4) satellite observations for sea-surface temperature and altimetry. Data from satellite-mounted altimeters (Figure 3a), moorings, and towed instrument systems showed important mesoscale processes.

One of the novel aspects of the U.S. JGOFS Arabian Sea study was the deployment of five moorings with meteorological and physical instruments covering a square roughly $55 \mathrm{~km}$ on a side (Dickey et al., 1998a). They were located near the axis of the atmospheric 
(a)

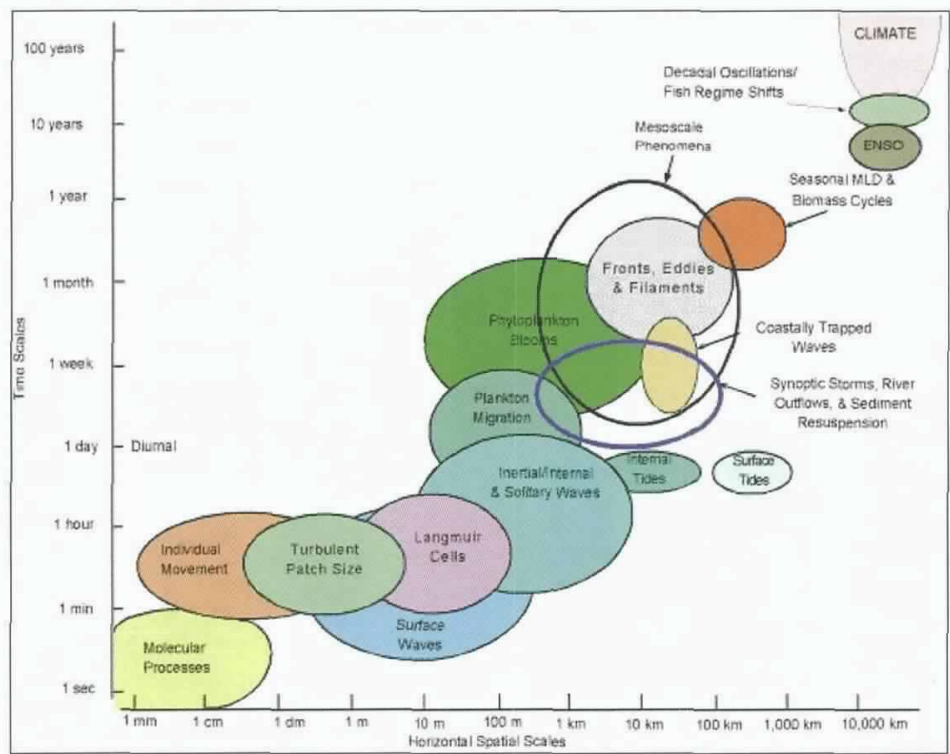

Figure 1. a) Time and space scales for ocean processes and phenomena that are relevant to biogeochemical cycling. $b$ ) Time and space scales suggesting the capabilities of various ocean sampling platforms.

(b)

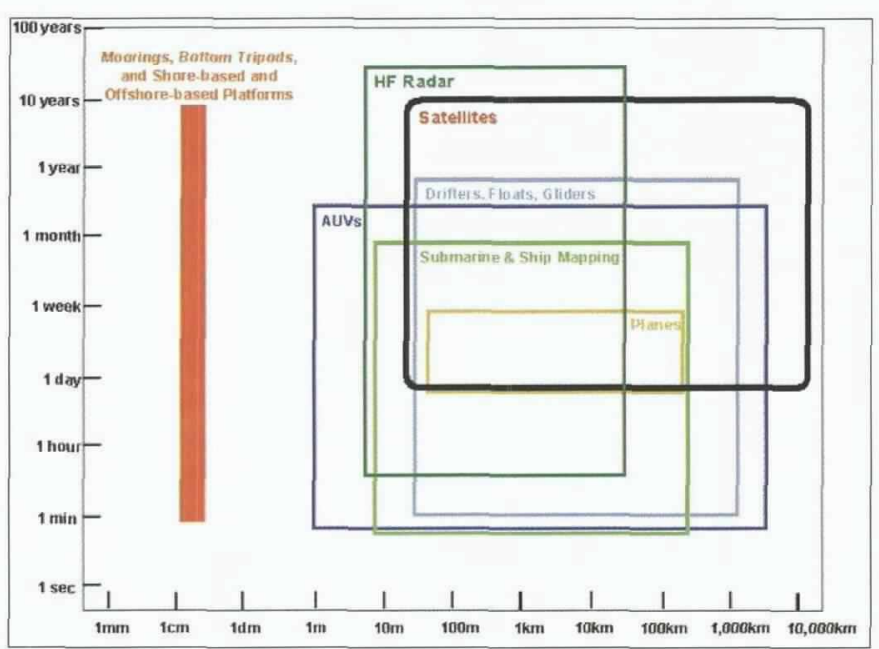

Findlater Jet. The central mooring, located at $15^{\circ} 30^{\prime} \mathrm{N}$, $61^{\circ} 30^{\prime} \mathrm{E}$, carried Multi-Variable Moored Systems (MVMS) at four depths in the upper $80 \mathrm{~m}$ of the ocean. Each MVMS (Figure $3 b$ ) included a vector-measuring current meter, a thermistor for temperature, a beam transmissometer to measure particle variability as related to primary productivity and particulate organic carbon, a strobe fluorometer to infer chlorophyll $a$ concentrations, a scalar irradiance sensor for PAR, an upwelling radiance sensor $(683 \mathrm{~nm})$ for natural fluorescence, and a pulsed dissolved oxygen sensor.

An important attribute of the MVMS is that it concurrently measures bio-optical, chemical and physical parameters at sampling intervals of a few minutes for periods of up to 6 months. It thus expands the temporal sampling to capture processes such as internal gravity waves, diel cycling, episodic wind events and phy- toplankton blooms, mesoscale eddies and associated primary production, and seasonal mixed layer and bloom evolutions. Samples were taken every few minutes with the central mooring's bio-optical, chemical, and physical instruments over an entire annual cycle (October 1994 through October 1995). The array of moorings was designed to quantify the spatial variability associated with the passage of mesoscale and other spatially varying features.

The physical mooring data show that the mixed layer deepens and shoals twice a year (Dickey et al., 1998a). The Northeast (NE) monsoon is characterized by steady northeasterly winds of moderate intensity ( 6 $\mathrm{m} / \mathrm{sec}$ ), surface cooling and convection, whereas the Southwest (SW) monsoon features strong, persistent southwesterly winds with greater intensity (up to 15 $\mathrm{m} / \mathrm{sec}$ ). The NE monsoon features deeper mixed layers 


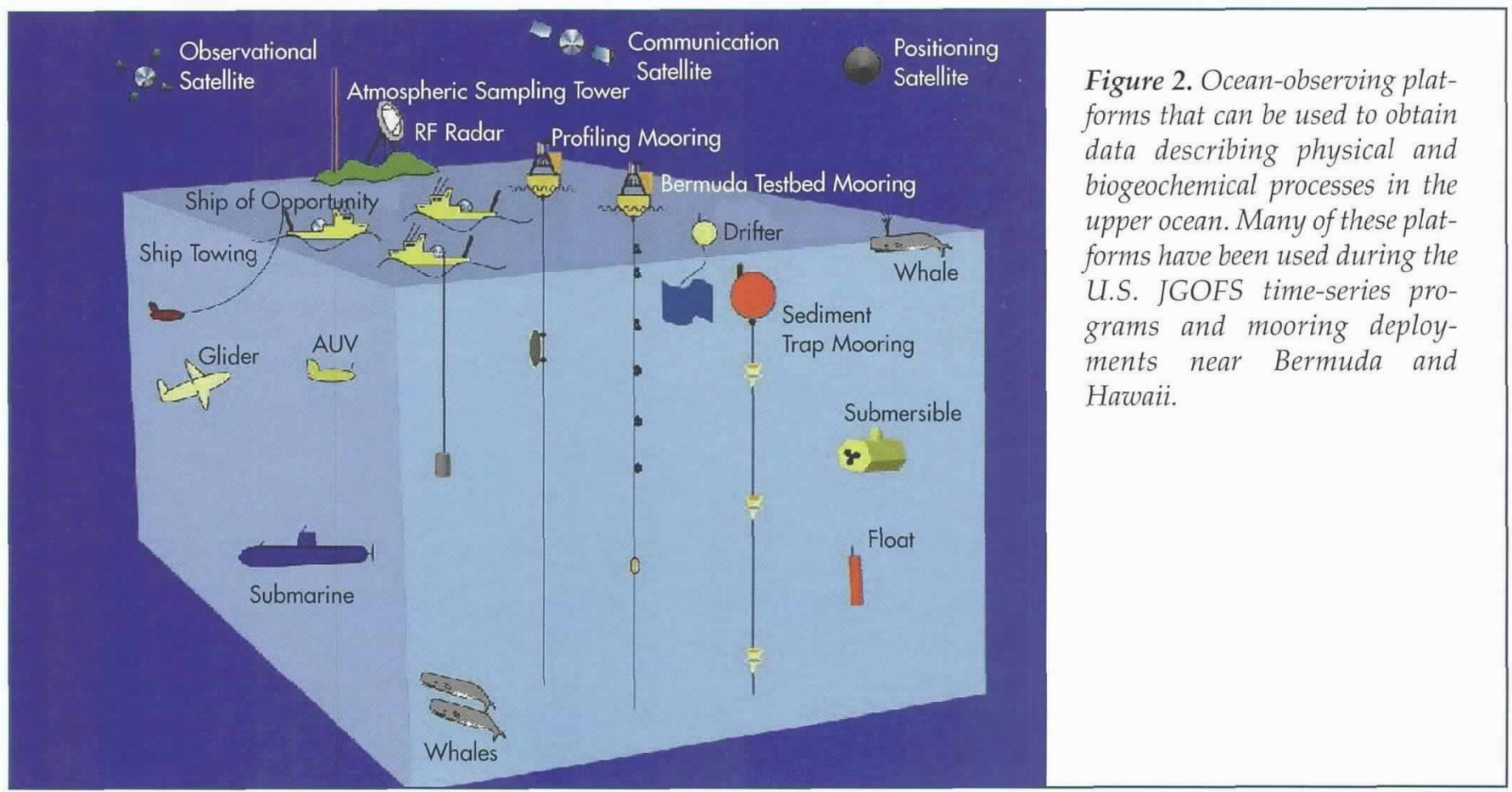

(a)

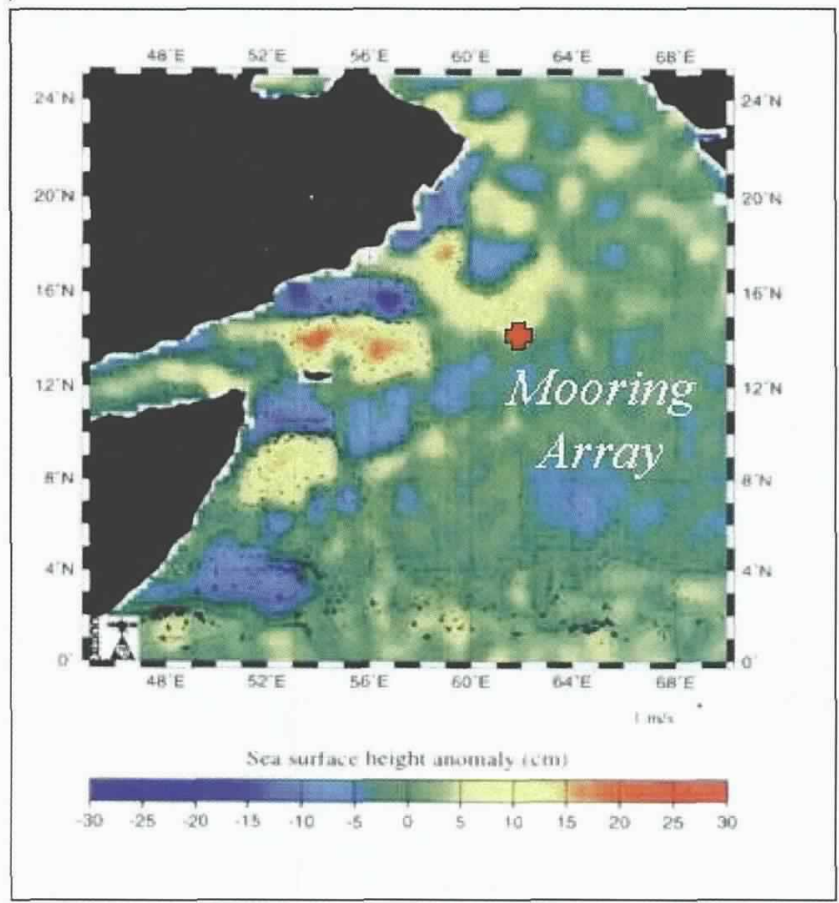

(b)

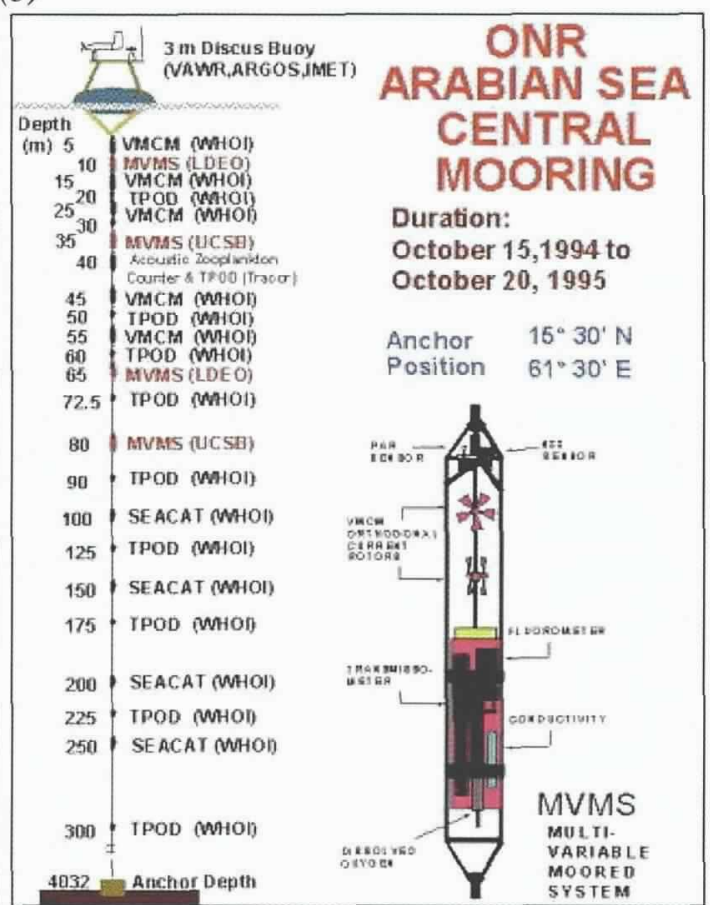

Figure 3. a) Map of the region studied during the U.S. JGOFS Arabian Sea process study. Sea-surface height anomaly data show considerable mesoscale variability in the region. The location of the mooring array used to collect physical, biooptical and biogeochemical data is indicated by the red cross (after Dickey et al., 1998a). b) Diagrams of the central mooring deployed at $15^{\circ} 30^{\prime} \mathrm{N}, 61^{\circ} 30^{\prime} \mathrm{E}$ and a Multi-Variable Moored System (MVMS). 
(110 $\mathrm{m}$ depth) than the SW monsoon (80 m depth) because of convective forcing. The MVMS data show that chlorophyll concentrations and primary production are correlated with the seasonal physical cycle associated with the NE and SW monsoons (Figure 4). A half-yearly cycle in chlorophyll $a$ concentrations is an important feature with seasonal blooms that occur late in each monsoon season and into the respective intermonsoon periods. The data show that depth-integrated chlorophyll $a$ generally tracks the 1\% light level.

One of the more interesting results of the Arabian Sea study was the discovery that mesoscale eddies play such an important role in the evolution of chlorophyll $a$ concentrations at the central mooring site (Figure 4). A sediment-trap mooring with serial samplers (see Berelson, this issue) at depths of 0.8, 2.2 and $3.5 \mathrm{~km}$ was located approximately $50 \mathrm{~km}$ north of the central mooring site by Sus Honjo (WHOI). The combined MVMS measurements of derived primary productivity and sediment trap samples indicate that the timing and amplitudes of phytoplankton blooms associated with seasonal stratification and eddies were strongly correlated (Honjo and Weller, 1997). This correlation suggests relatively rapid (days to weeks) export of organic carbon to the deep ocean. Complementary estimates of the shallow export flux of POC at $100 \mathrm{~m}$ were obtained in the Arabian Sea using the recently developed Thorium-234 method. The Thorium-234 data indicated that the single greatest feature of the annual cycle was a basin-wide POC export peak that occurred during the late SW monsoon (Buesseler et al., 1998).

Spatial data were derived from underway ship transects with SeaSoar (Figure 5), ADCP transects and satellite sea-surface temperature and altimetry sensors. SeaSoar, a towed undulating platform, was used by both British and U.S. oceanographers (Lee et al., 2000) in the Arabian Sea. In both cases, suites of physical, bio-optical, chemical and acoustical sensors were interfaced to SeaSoar platforms. The bio-optical and chemical sensors were similar to those deployed on the MVMS packages. In addition, acoustic backscatter data obtained from the ADCPs were utilized to estimate zooplankton biomass and their diel migrations. Multifrequency acoustic sensors developed by Van Holliday were deployed aboard the SeaSoars to determine zooplankton distributions by size classes.

Spatial and temporal data obtained from these platforms indicate that the region is especially rich in mesoscale features whose origins are probably linked to westward-propagating Rossby waves and coastal filaments and jets that reach far offshore eastward from the Oman coast. Lee et al. (2000) carried out an objective analysis using SeaSoar chlorophyll transect data during the fall intermonsoon of 1995. This analysis emphasizes the power of virtually continuous transect data for resolving patchiness; it also warns of the errors (e.g., aliasing) likely to result from reliance on standard ship-based sampling on coarse grids $(>100 \mathrm{~km})$.

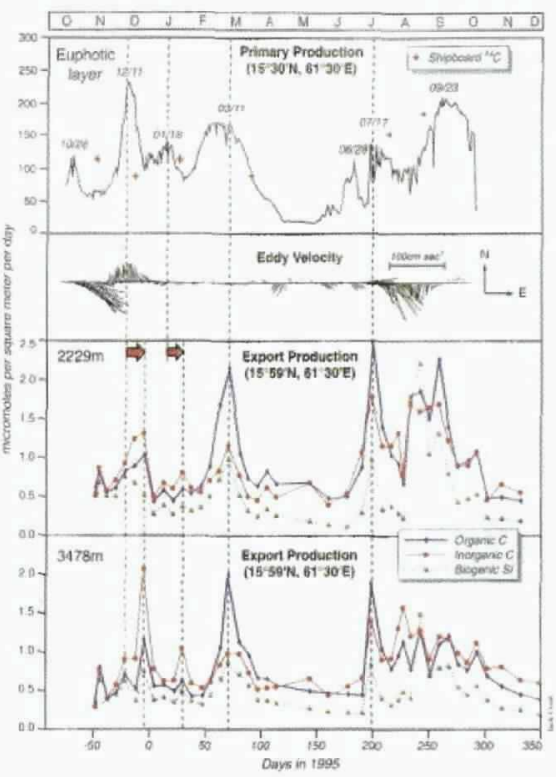

Figure 4. Time-series data from moored sensors in the Arabian Sea. Top panel: primary production obtained from Multi-Variable Moored System (MVMS) data and a model. Upper middle panel: currents at $35 \mathrm{~m}$, indicating passages of eddies. Lower middle panel: export production at $2229 \mathrm{~m}$ obtained from a sediment-trap mooring, and Bottom panel: export production at $3478 \mathrm{~m}$ from the same sediment-trap mooring. (Figure after Honjo and Weller, 1997)

Previous papers describing high-frequency bio-optical data sets have made the same point in the temporal domain (e.g. Dickey, 1991).

\section{Innovations of Two North Atlantic Experiments}

The international JGOFS North Atlantic Bloom Experiment (NABE) was carried out in 1989 with a central objective of studying the spring phytoplankton bloom and its associated biogeochemical effects in the North Atlantic, one of the largest transient signals on earth (Deep-Sea Research II, 40[1-2], 1993). NABE observations were carried out at seven primary locations between about $18^{\circ} \mathrm{N}$ and $72^{\circ} \mathrm{N}$, roughly along $20^{\circ} \mathrm{W}$. A second experiment, The Marine Light in the Mixed Layer (MLML) study, was motivated by the desire to improve the understanding of upper ocean bio-optical variability and bioluminescence as affected by physical forcing at high latitudes (Dickey et al., 1994). MLML was conducted primarily at a site south of Iceland at $59^{\circ} \mathrm{N}, 21^{\circ} \mathrm{W}$. Although MLML was not part of NABE, the field studies had several objectives in common and overlapped in time in the spring of 1989. One of the methodological innovations of the NABE and MLML studies was the use of diverse sampling platforms, including ships, aircraft equipped with Light Detection 


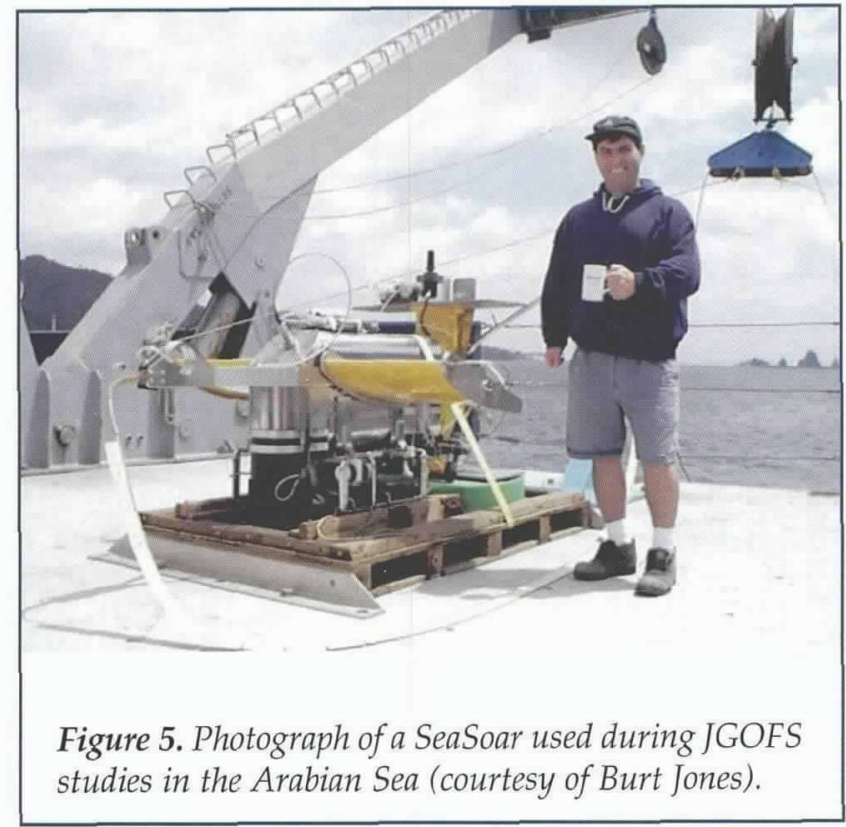

and Ranging (LIDAR), drifting sediment traps, a satellite with an altimeter and a multidisciplinary mooring similar to one described above. The collective data sets and models were used to characterize and analyze the temporal and spatial complexities of the spring bloom.

NABE data show that mesoscale eddies and mixed layer variability are important for phytoplankton blooms and ecosystem dynamics (see McGillicuddy, this issue; Dickey et al., 1994). Refinement of techniques for measuring $\mathrm{CO}_{2}$ at sea, and seasonal and spatial changes in the partial pressure of $\mathrm{CO}_{2}$ during NABE made it possible to demonstrate links between variability in $\mathrm{CO}_{2}$ levels and the dynamics of the spring bloom in the North Atlantic (see Feely et al., this issue). Similar advances in seagoing instrumentation were made in the measurement of DOC (see Hansell and Carlson, this issue). In addition, microbial activities were found to be important during the blooms. Moorings at $34^{\circ} \mathrm{N}$ and $47^{\circ} \mathrm{N}$ (Sus Honjo) were used to deploy deep sediment traps that captured variability in particle fluxes at various depths.

The MLML field program, carried out from April to June, 1989, and from May to September, 1991, utilized MVMS packages on moorings to obtain high-resolution data over time at eight depths (Dickey et al., 1994). Although the high-latitude location with its high winds and large waves presented a major technological challenge for moored observations, excellent biooptical and physical time-series data were obtained. The abrupt onset of spring stratification with shoaling of the mixed layer was dramatic (from $550 \mathrm{~m}$ to $50 \mathrm{~m}$ within 5 days), illustrating the importance of high temporal resolution sampling with moorings. The moored instruments also captured the onset of a phytoplankton bloom, apparently associated with modest nearsurface stratification, prior to the major springtime shoaling of the mixed layer and the seasonal spring bloom. An increase in near-surface temperature of $0.2^{\circ} \mathrm{C}$ accompanied the phytoplankton increase, a change suggested by model studies but previously unobserved because of sampling limitations.

In the MLML field program, the mooring observations were complemented by shipboard profiles and ship tow-yo sections, LIDAR measurements from P-3 aircraft and satellite sea-surface temperature data (Dickey et al., 1994). These data provided context for the mooring data as well as information on horizontal features and scales of variability. For example, the LIDAR data showed that there were patches of high concentrations of chlorophyll a with horizontal scales on the order of $30 \mathrm{~km}$. The NABE and MLML programs represent an early attempt to develop observational strategies for fully three-dimensional, interdisciplinary time-series programs, one of the themes of this review.

\section{The Equatorial Pacific}

The JGOFS equatorial Pacific process study took place in 1992, and related studies preceded and followed the main field program (Deep-Sea Research II, 1995: 42[2-3], 1996: 43[4-6], 1997: 44[9-10]). Field experiments were conducted in the central and eastern Pacific from $95^{\circ} \mathrm{W}$ to $170^{\circ} \mathrm{W}$ between $10^{\circ} \mathrm{N}$ and $10^{\circ} \mathrm{S}$. The equatorial Pacific is affected by a great variety of physical and climatological processes, including El Niño-Southern Oscillation (ENSO) cycles. It also plays an important role in the global carbon cycle. Estimates suggest that the region supplies roughly one gigaton of carbon $\left(\mathrm{as}_{2}\right)$ to the atmosphere each year, primarily due to the upwelling of carbon-rich deep water along the equator. The equatorial Pacific is also a High Nutrient-Low Chlorophyll (HNLC) region; its productivity and carbon fluxes are small relative to the supply of nutrients.

The physical dynamics of the equatorial Pacific have become increasingly well understood over the past two decades, largely due to measurements made by the Tropical Atmosphere Ocean (TAO) mooring array. However, understanding of biological and optical variability has been limited because few dedicated ship-based experiments could be performed in such a remote region. In particular, typically only a few biological observations of chlorophyll and primary productivity were made each year prior to JGOFS; hence, these were our only basis for annual estimates of chlorophyll and primary production for the expansive Pacific equatorial waveguide. With this motivation, MVMS packages were installed on the TAO physical mooring at $0^{\circ}, 140^{\circ} \mathrm{W}$ for an 18 -month period during 1992 and 1993 (Foley et al., 1997). The timing of our sampling period was most opportune as the observations spanned both El Niño and "normal" phases of the ENSO cycle. During the El Niño phase, the mixed layer, the thermocline and a very weak Equatorial Undercurrent (EUC) were deep, at times in excess of $150 \mathrm{~m}$. Kelvin waves with a roughly 60-day period propagated eastward past the site, accompanied by depressions of the thermocline. Time-series measure- 
ments of key physical and bio-optical parameters obtained from instruments deployed on the mooring $\left(0^{\circ}, 140^{\circ} \mathrm{W}\right)$ are shown in Figure 6. Light levels were high, but nutrients, including iron, were only elevated in deep waters. As a result, chlorophyll $a$ concentrations in the upper layer were low (less than $0.2 \mathrm{mg} \mathrm{m}^{-3}$ ).

As "normal" conditions returned to the region, Kelvin waves ceased. The thermocline and a strong EUC shoaled, allowing transport of nutrients into the euphotic zone. Westward propagating Tropical Instability Waves (TIW) with periods of roughly 20 days also contributed to large vertical upwelling cycles. TIWs are easily seen in the meridional current records, and appear to be manifest in the time-series data with chlorophyll $a$ values double and at times triple those observed during the El Niño period (Figure 6). Importantly, strong, though highly complex, coupling is evident between the physical processes (El Niño, Kelvin waves and TIWs) and the phytoplankton biomass and primary productivity (here roughly proportional to chlorophyll $a$ ) of the equatorial Pacific.
Passages of TIWs may be envisioned as natural iron enrichment experiments.

Newly developed bio-optical drifters released at the equatorial mooring site provided spatial data as they drifted poleward, enabling estimates of net phytoplankton growth rates. Ship measurements benefited from improved measurement systems for $\mathrm{pCO}_{2}$ as well as from underway shipboard ADCP data sets. Estimates of export flux of POC were based on the thorium-234 method described earlier. Results of the thorium-234 study indicate considerable spatial and temporal variability in export of organic carbon, which was highest at the equator. They also show that a relatively low percentage of total production $(<5-10 \%)$ is exported via sinking particles. The combination of the instrumented TAO mooring array with JGOFS shipboard sampling and sediment traps provided a relatively comprehensive, though coarse, threedimensional biogeochemical time-series data set for the region.

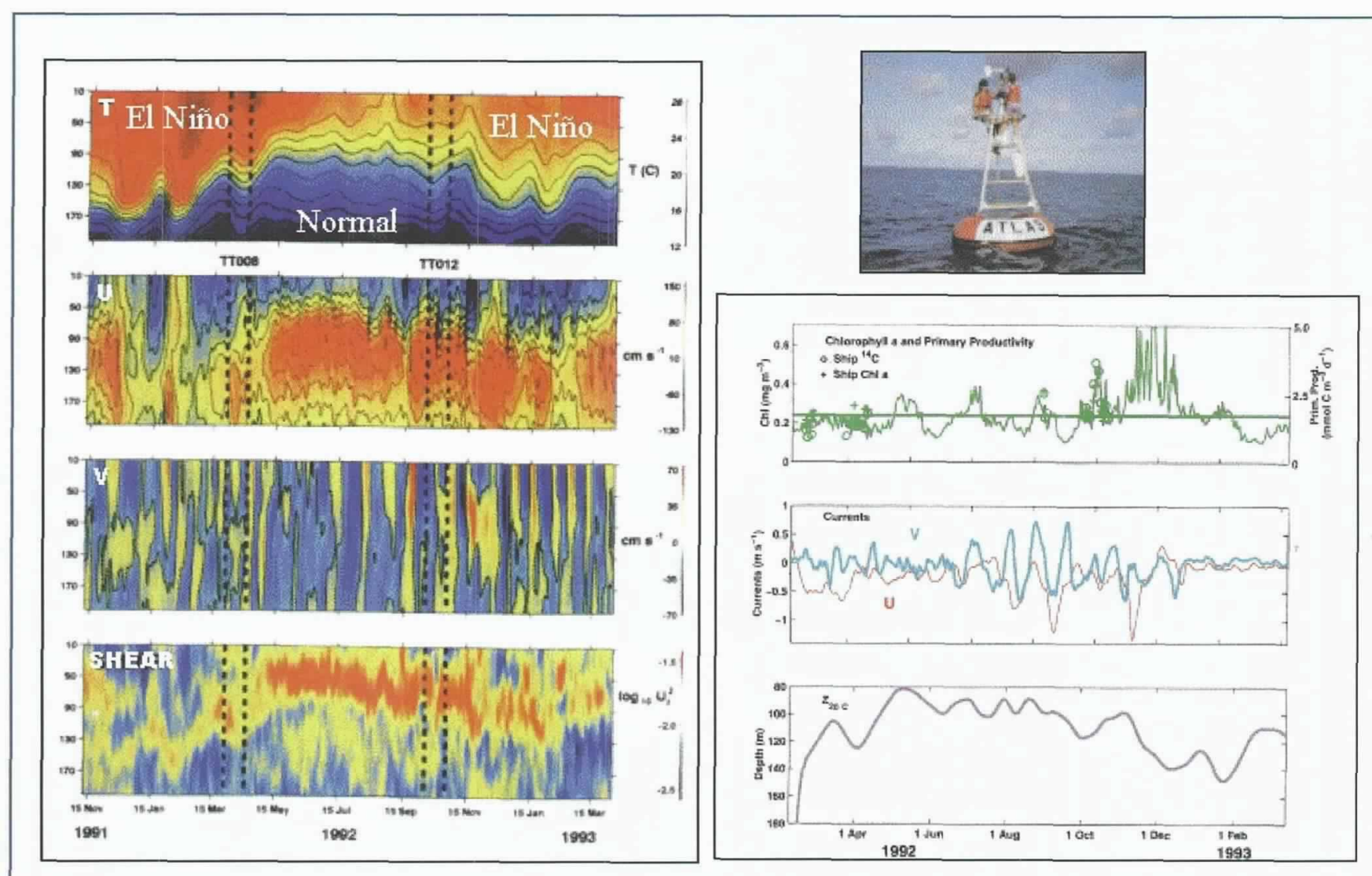

Figure 6. Data collected during the U.S. JGOFS Equatorial Pacific Process Study from a mooring at $0^{\circ}, 140^{\circ} \mathrm{W}$ (Foley et al., 1997). Left, top to bottom: Time versus depth contour plots of temperature, zonal currents, meridional currents and current shear. Black vertical dashed lines indicate periods of concurrent shipboard sampling at the site. Right, top to bottom: ATLAS mooring, chlorophyll a and derived primary productivity at $10 \mathrm{~m}$, zonal (red) and meridional (blue) currents at $10 \mathrm{~m}$, and depth of the $20^{\circ} \mathrm{C}$ isotherm, which deepens during El Niño periods. 


\section{The Southern Ocean}

The Southern Ocean is generally thought to be one of the most important and sensitive oceanic regions in regard to the carbon budget and climate in general. The Southern Ocean was targeted for study by the JGOFS program because it is likely an ocean of globally significant carbon fluxes, yet it remains a region about which the factors regulating carbon fluxes are less well known (data sparse) than is the case for more readily accessible oceans. Major questions concerning the biogeochemistry of the Southern Ocean remain unanswered: 1) Does the Southern Ocean act as a net source or sink for atmospheric $\mathrm{CO}_{2}, 2$ ) What is (are) the limiting factor(s) for primary productivity (note that the Southern Ocean is a high nutrient-low chlorophyll (HNLC) region), and 3) How does biological variability affect the upper ocean's heat budget?

The JGOFS Southern Ocean field studies used many of the sampling platforms and instruments described above; thus only a couple of new sampling methodologies are noted here. The long-awaited Sea Viewing Wide Field-of-View (SeaWiFS) ocean-color instrument, launched in August 1997, provided largescale information on surface pigments for JGOFS Southern Ocean cruises (see Yoder et al., this issue). Recognizing the importance of capturing migrating frontal features and mesoscale variability, Mark Abbott and his colleagues (2000) deployed an array of 12 moorings, spaced $30 \mathrm{~km}$ apart, and equipped with physical and bio-optical sensors in the Antarctic Polar Frontal Zone (APFZ) from November 1997 to March 1998. These moorings differed from others described above in that they were subsurface, relatively lightweight, carried fewer sensors and were relatively easy to deploy and recover under adverse conditions. The mooring array captured a strong spring bloom beginning in December 1997.

The mooring data, together with data sets collected aboard ships, suggest that light levels limit phytoplankton populations initially because of deep mixing. Then silicate concentrations or zooplankton grazing become limiting factors, followed finally by iron limitation. The spring bloom at the polar front in 1997-98 lasted only a few weeks, which supports the argument for the fast sampling rates possible with autonomous moored instruments. The mooring array proved important in a region where both temporal and spatial scales are small.

\section{Bermuda Testbed Mooring and HALE-ALOHA Mooring Programs}

The JGOFS Bermuda Atlantic Time-series Study (BATS) and the Hawaii Ocean Time-series (HOT) study, both launched in 1988, have been used to observe, quantify and model temporal changes in the biogeochemical and ecological properties of the subtropical oligotrophic gyres of the North Atlantic and the North Pacific (see Karl et al., this issue; Deep Sea Research II, 1996: 43[2-3]; 2001: 48[8-9]). Both of these programs have relied primarily on shipboard sampling at two- to four-week or longer intervals. But this mode of observation cannot capture important phenomena with time scales from minutes to a month. For this reason, investigators established high-frequency, longterm, autonomous moored sampling programs at both sites. The first was the Bermuda Testbed Mooring (BTM); Tommy Dickey and Dan Frye (WHOI), shown in Figure 7, launched in 1994 at the BATS site (Dickey et al., 1998b; Dickey et al., 2001). A similar mooring, HALE-ALOHA, was established in 1996 at the HOT site (Letelier et al., 2000) by David Karl (University of Hawaii) and colleagues.

These two mooring efforts have clearly demonstrated the importance of events and processes that cannot be captured or resolved by bi-weekly or less frequent shipboard sampling. These events and processes include mesoscale eddies, storms, hurricanes, dust deposition events, rapid shoaling of the mixed layer and transient phytoplankton blooms, inertial oscillations, diel and shorter-term variability in phytoplankton and bio-optical properties, and internal gravity waves. Data from both the BTM and the HALEALOHA mooring have documented passages of mesoscale features with high nutrient and phytoplankton concentrations. The BTM time-series data shown in Figure 8 highlight both the passage of a major eddy and its effects on nutrients and phytoplankton biomass in July 1995 and the upper-ocean response to Hurricane Felix, which passed over the BTM in August 1995.

The original aim of the BTM program was to create an opportunity for long-term testing of multidisciplinary autonomous sensors and systems. The BATS site was chosen because of the regular BATS shipboard sampling program and the long-term sediment trap data collected nearby by Werner Deuser and Maureen Conte (WHOI) since 1978. The BTM is used to collect meteorological, physical and bio-optical data every few minutes, including temperature, conductivity, currents, PAR and chlorophyll fluorescence. A complementary project, Ocean-Systems for Chemical, Optical and Physical Experiments (O-SCOPE), has used the BTM to test several proto-type chemical and optical sensors.

Among the systems being tested, as part of the BTM program are newly developed moored bio-optical sensors that include several spectral absorption and attenuation meters ( 9 to 100 wavelengths over the visible spectrum) for measuring inherent optical properties. Also being tested are spectral irradiance and radiance radiometers (Figure 9a) for measuring apparent optical properties at several wavelengths matched to those sampled by the SeaWiFS ocean color instrument.

Derived data resulting from the BTM program include chlorophyll a concentrations, spectral radiance and irradiance ratios, spectral diffuse attenuation coefficients and spectral water-leaving radiance. The latter data have been used for validation and algorithm development for the SeaWiFS instrument. The BTM data are virtually continuous and provide a large num- 


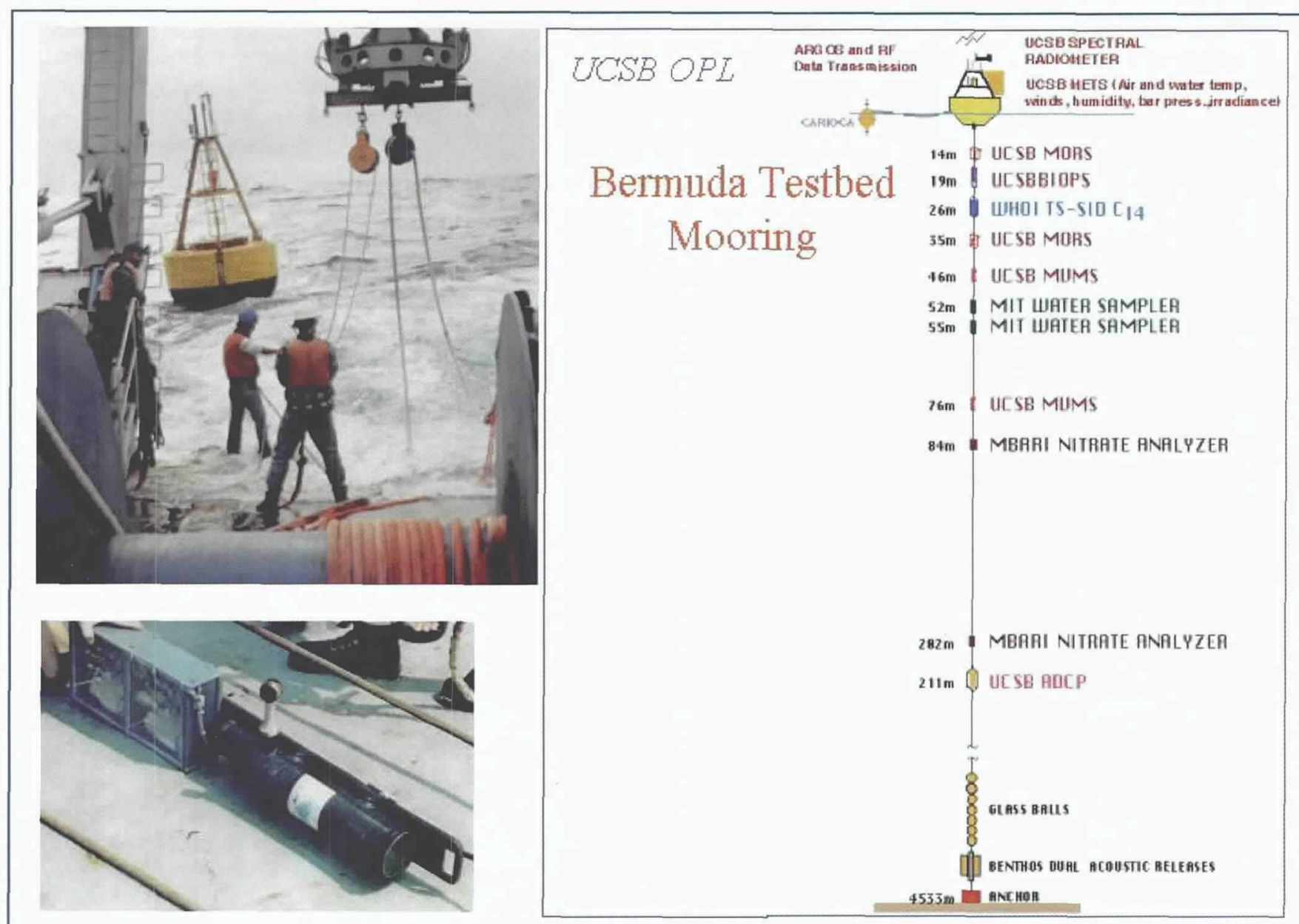

Figure 7. Upper left: Bermuda Testbed Mooring (BTM) surface buoy during deployment. Lower left: Osmoanalyzer for measuring nitrate, developed by Hans Jannasch and colleagues. Right: Schematic diagram for a BTM deployment.

ber of match-ups. The radiometric data are especially important because satellite-based measurements of ocean color are limited to the uppermost ocean layer (roughly one optical depth), and viewing is limited by cloud cover. In addition, data have been collected by other new optical systems tested at the BTM; these systems include a spectral volume scattering function instrument and a spectral fluorometer (6 excitation and 16 emission wavelengths).

One of the major limitations for moored optical systems has been biofouling. Recently copper shutter systems and tubing for pumped systems have been engineered and tested. Results indicate that the duration of deployments can be extended to at least six months (as opposed to three to four months) in oligotrophic waters.

Several new chemical systems and sensors have been deployed on the BTM (Dickey et al., 1998b; Dickey et al., 2001). An in situ autonomous sampling colorimetric system, Osmoanalyzer (Figure 7; Hans Jannisch, MBARI), has collected time-series data on nitrate and nitrite concentrations with a 10- or 15minute sampling interval. The Osmoanalyzer utilizes osmotic pumps that propel both sample and reagent fluids through a miniature flow-injection manifold. Our understanding of the biogeochemistry of eddies, particularly nitrate injection and subsequent phytoplankton growth, has been improved by data from the Osmoanalyzer as well as the bio-optical and physical data collected with instruments on the BTM (Figure 8).

Four different groups have tested autonomous $\mathrm{pCO}_{2}$ sampling systems at the BTM (Tokar and Dickey, 2000; Varney, 2000). One of these (called CARIOCA; Liliane Merlirat, University of Paris), which involves a separate buoy tethered to the BTM, has shown variability in $\mathrm{pCO}_{2}$ on diel and synoptic time scales. A system for measuring the difference between atmospheric and surface-water $\mathrm{pCO}_{2}$ levels (Gernot Friederich) was tested during a BTM deployment in the summer and fall of 2000. Resulting time-series data suggest that the usual summertime supersaturation of surface-water $\mathrm{CO}_{2}$ was interrupted during most of July when $\mathrm{pCO}_{2}$ values returned to near atmospheric levels. During autumn, temperature and $\mathrm{pCO}_{2}$ decreased in concert. Dissolved oxygen sensors have also been tested.

Investigators have deployed a new Moored In situ 

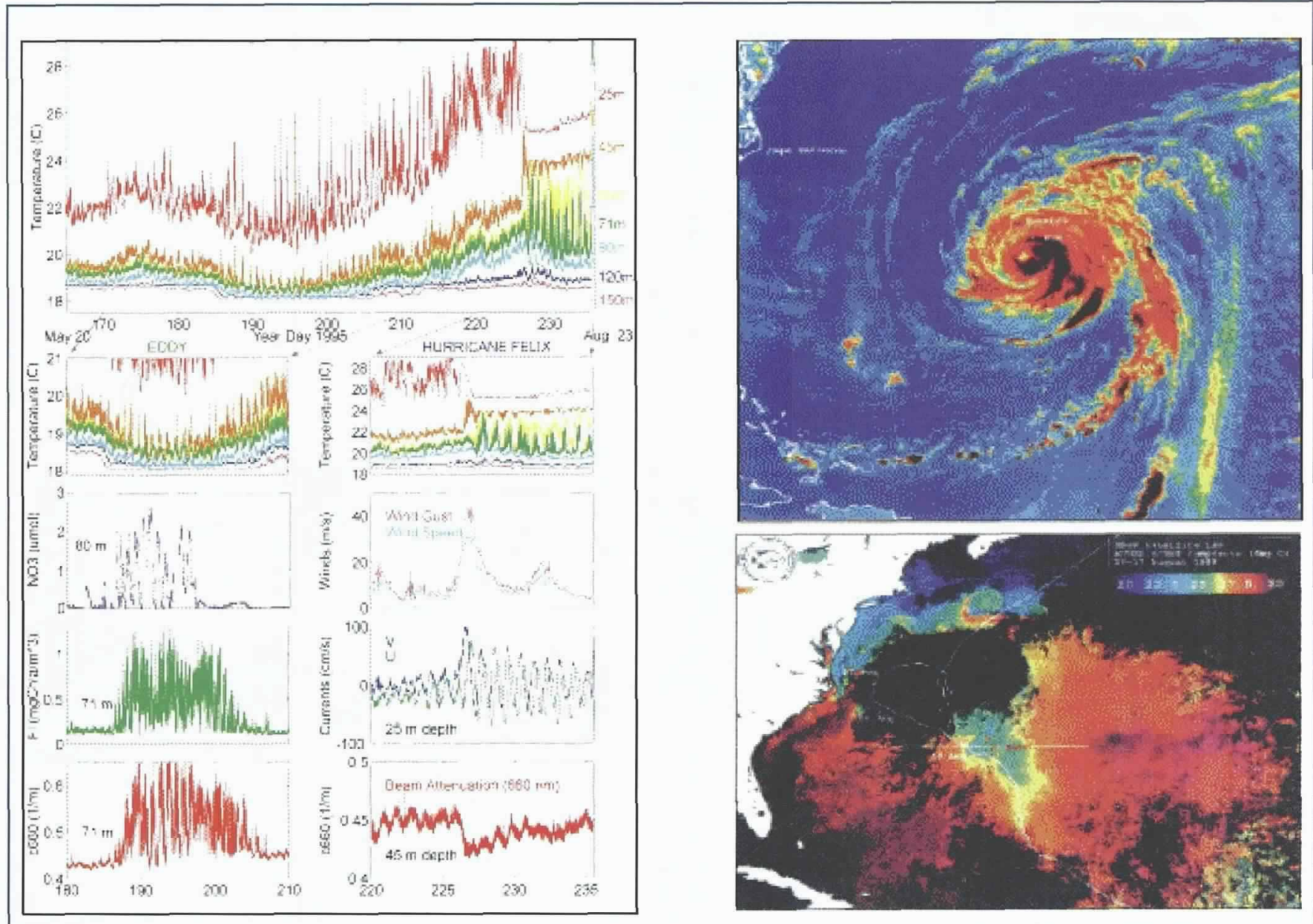

Figure 8. Upper left panel shows Bermuda Testbed Mooring (BTM) temperature data from the summer and fall of 1995. Lower far left panels show BTM data collected during the July passage of a mesoscale eddy with exceptionally high nitrate, chlorophyll and beam attenuation coefficient $(660 \mathrm{~nm})$ values at $80 \mathrm{~m}$ (McNeil et al., 1999). Lower near left panels show BTM temperature, wind, current and beam attenuation coefficient data, during the passage of Hurricane Felix in August 1995 (Dickey et al., 1998b). Upper right panel shows a satellite image of the passage of Hurricane Felix over the BTM. Lower right panel shows a satellite image of sea surface temperature. Cooling of the upper layer in the wake of Hurricane Felix is evident. (Satellite images courtesy of Norm Nelson)

Trace Element Serial Sampler (MITESS), developed by Edward Boyle (MIT), on both the BTM and HALEALOHA moorings. The purpose of the MITESS (Figure 9b) is to track the temporal variability of trace metals in the upper ocean. The system consists of 12 independent sampling modules, made of ultra-high molecular weight polyethylene, mounted on a durable mooring unit. Two MITESS units have been deployed simultaneously from the BTM to increase sampling frequency. Samples are preserved and returned to the laboratory at MIT for analyses. Results from the MITESS and previous sampling at the BTM site indicate that lead concentrations off Bermuda have decreased substantially since restrictions on leaded gasoline were enacted in the United States. Also, MITESS data from both BTM and HALE-ALOHA moorings have shown considerable variability in iron concentrations, apparently relat- ed to the passage of eddies, transient wind forcing and bloom events (Edward Boyle, pers. comm).

Another instrument deployed from the BTM is the Time-Series Sampler Incubation Device or TS-SID (Figure 9c) that was developed to measure primary production using autonomous carbon-14 $\left({ }^{14} \mathrm{C}\right)$ observations. Simultaneous TS-SID ${ }^{14} \mathrm{C}$ productivity and biooptical data have been collected from the BTM and are being used to investigate variability in photosynthetic parameters ( $\mathrm{a}^{*}$ and $\Phi$ in equation 1 ) in ongoing work by Craig Taylor (WHOI) and Tommy Dickey. The data sets collected by the BTM and ALOHA-HOST programs have led to exciting discoveries and are being used for several modeling studies.

\section{Data Telemetry}

The telemetry of data in near real-time has become 


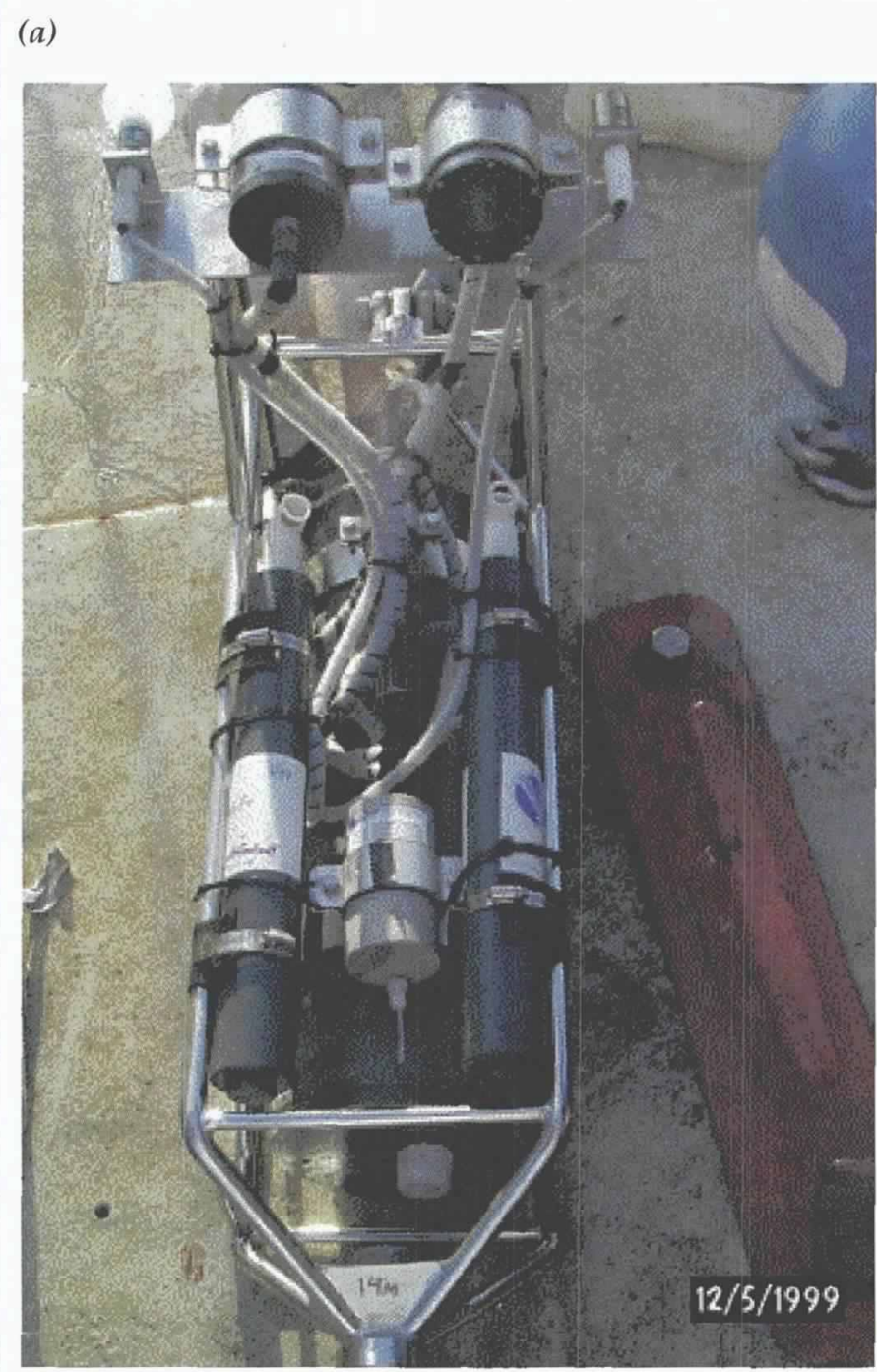

(b)

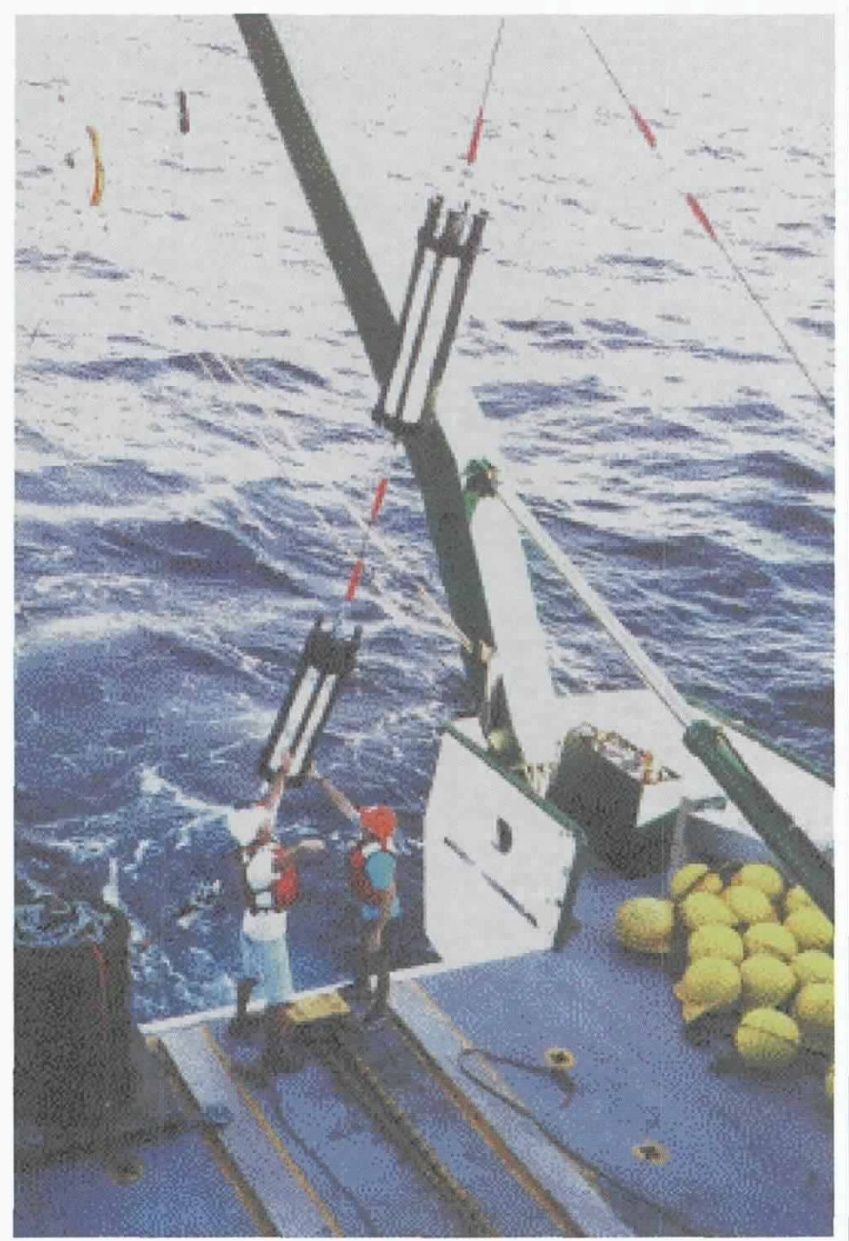

Figure 9. a) Photograph of an instrument package before deployment from the Bermuda Testbed Mooring (BTM) with spectral irradiance and radiance, Photosynthetically Available Radiation $(P A R)$, dissolved oxygen and temperature sensors. b) Deployment of the Moored In situ Trace Element Serial Sampler (MITESS), a trace metal sampler on BTM (courtesy of Edward Boyle). c) Time-series sampler incubation device, developed by Craig Taylor and Kenneth Doherty.

(c)

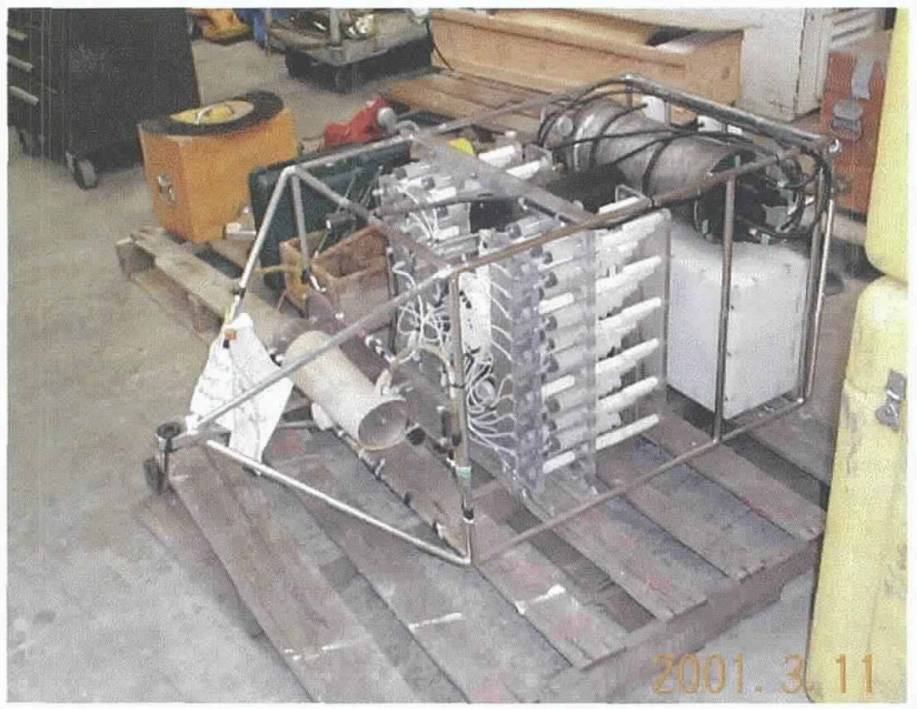


increasingly desirable for many purposes, including data assimilation models for predictions, establishing ground truth for ocean-color sensors aboard satellites, directing observations at sea and warnings to the public of hazardous conditions. Use of fiber-optic and electrical cable data transmission methods is practical for coastal locations, sites near seafloor communication cable junctions or special study areas.

Participants in the BTM project (including Dan Frye, WHOI, and Tommy Dickey) have tested a variety of telemetry systems (Dickey et al., 1998b), including in situ systems using acoustic modems and inductive electrical coupling via toroidal pick-ups on the mooring line for transmitting data from subsurface instruments to the BTM surface buoy. Data have been stored in a data-logging system on the buoy for subsequent transmission, either to $\mathrm{R} / \mathrm{V}$ Weatherbird II for later transmission to land stations, or via satellite (Argos Data Collection System) links to these stations. One of the interesting features of the new system is its twoway communication capability; commands can be sent to the in situ instruments. For instance, this system was used at the BTM site as a signal from Monterey, California, was sent to the BTM in order to change an Osmoanalyzer setting.

Two-way communications systems can also be used to change sampling frequencies so that more samples can be taken during passages of eddies or hurricanes. Presently, bandwidth is limited, so that only small subsets of data can be transmitted. This problem should be solved in the next few years, possibly with a constellation of low earth-orbiting communications satellites. Many autonomous ocean sampling platforms are facing the same problem. Scientists from a variety of disciplines want access to data in near realtime from moorings, profiling floats, gliders, AUVs and other ocean platforms.

In addition, the BTM/BATS site was used for testing the Southampton Oceanographic Centre's AUV, Autosub, which included bio-optical sensors (Griffiths et al., 2000), and evaluation of a new neutrally-buoyant sediment trap designed to reduce the effects of hydrodynamic flow interference (Valdes et al., 1997). We anticipate that the BTM and the Hawaii mooring programs will be used in the future for similar studies requiring in situ validation of data from sensors deployed on profiling floats, AUVs and gliders.

\section{Future Technologies}

Considerable progress has been made in answering the complex questions posed at the beginning of JGOFS, thanks in large part to new instruments and methods of observation. Yet much remains to be learned and explained. The direction of future technologies and observations will be driven by many new questions stimulated by JGOFS studies. Further research is needed to expand scientific knowledge about factors that control primary productivity and nutrient cycles, the efficiency of the biological pump for different foodwebs, and the roles of physical processes that affect biogeochemical processes. A good starting point for looking toward the future is to reconsider time-space diagrams for processes and platforms (Figures $1 \mathrm{a}$ and $\mathrm{b}$ ). In the next sections, we consider the platforms and then sensors and systems.

\section{Platforms}

An important, though ambitious, goal is to develop integrated ocean sampling systems that can collect multidisciplinary time-series data in all three spatial dimensions for the global ocean. The collective platforms illustrated in Figure 2 can, in principal, support observations over a fair portion of the time and space domains illustrated in Figure 1. We have seen an explosive growth in the development and capabilities of autonomous sampling platforms in recent years, including profiling drifters, floats, moorings, AUVs, and gliders. The ARGO program plans to launch 3,000 profiling floats to collect profiles of temperature and salinity as well as Lagrangian current information throughout the global ocean. Plans for time-series moorings, at carefully selected sites, are also underway. Gliders and AUVs are likely to play increasing roles as well. Satellites will provide higher spatial resolution data for more variables including ocean properties like salinity and specific groups of phytoplankton.

The increasing number of ocean platforms is providing oceanographers with unprecedented sampling opportunities. Nonetheless, we cannot yet achieve a continuous spectrum of sampling in time and space, and synoptic observations will remain a problem. The way forward will likely entail the use of diagnostic inverse models and numerical data assimilation models that can be used as "data interpolators" and for ocean predictions. Telemetry of data will be critical, and sophisticated networking of observational systems will be required to optimize sampling.

\section{Sensors and Systems}

Because of increased demand for interdisciplinary data, new efforts have begun to capitalize on available platforms for multidisciplinary measurements. Moorings have been especially attractive because of their carrying capacity and the relative ease of getting access to and interpreting data. A number of large instruments with substantial power demands have been adapted for mooring deployment; many were originally developed for laboratory use or vertical profiling from ships. However, many of the present instruments cannot be accommodated on drifters, profiling floats, AUVs or gliders. New questions stimulated by JGOFS and other biogeochemical programs require measurements of even more variables, including those needed for identification of bacteria, phytoplankton and zooplankton, nutrients such as phosphate, silicate and iron, and additional chemical properties such as $\mathrm{CO}_{2}, \mathrm{pH}$ and alkalinity.

It is essential that we develop a new class of sensors 
and systems. These must be small, inexpensive and have low power requirements. Exciting work is underway to meet these needs. Devices such as in situ flow cytometers, mass spectrometers and DNA analyzers are being developed for deployment on moorings and AUVs. Sensors that use fiber optics are also being developed for several ocean chemical measurements. And "chip-based," MicroElectroMechanical System (MEMS) and "nano" technologies still await application to oceanographic questions (Tokar and Dickey, 2000). Moored water samplers, such as MITESS, that are capable of preserving samples for long periods of time, will also be needed to provide samples for analyses that cannot be conducted in situ.

\section{Summary}

The original U.S. JGOFS Long Range Plan envisioned the use of moorings as platforms for autonomous sampling of bio-optical and biogeochemical parameters at the time-series stations and during the process studies. These moorings would be continued as long-term sampling components. At present, JGOFS autonomous moorings measurements are only being made by the BTM program at the BATS site, largely because of previous technological and budgetary limitations. It is imperative that resources for developing and implementing global biogeochemical sampling networks come from a variety of sources or organizations, international as well as domestic. Several of the new sensors, systems, and platforms described earlier are under development or in the hands of just a few researchers. These technologies need to be produced on a commercial scale. Interpretation of many of the signals of these new instruments remains an issue; intensive validation and inter-calibration efforts by scientists are needed.

One interesting benefit of advanced technologies may well be the development of simpler interdisciplinary sampling systems, such as chip-based sensors or nanosensors with automated data processing and telemetry components. These exciting new technologies could greatly benefit all oceanographic programs regardless of their present technical capabilities. Despite the numerous challenges we face, the oceanographic community has never been in a stronger position to make major advances in understanding ocean biogeochemistry. [D]

\section{Acknowledgements}

The present work has benefited greatly from interactions with numerous U.S. and international collaborators and colleagues. My research has been supported by the National Science Foundation, the U.S. Office of Naval Research, the National Aeronautics and Space Administration, the National Oceanic and Atmospheric Administration, the Minerals Management Service and the University of California, Santa Barbara. This is U.S. JGOFS Contribution Number 680.

\section{References}

Abbott, M.R., J.G. Richman, R.M. Letelier and J.S. Bartlett, 2000: The spring bloom in the Antarctic Polar Frontal Zone as observed from a mesoscale array of bio-optical sensors. Deep-Sea Res. II, 47[15-16], 3285-3314.

Behrenfeld, M. and P.G. Falkowski, 1997: A consumer's guide to phytoplankton primary productivity models. Limnol. Oceanogr., 42[1], 1-20.

Buesseler, K., L. Ball, J. Andrews, C. Benitez-Nelson, R. Belastock, F. Chai and Y. Chao, 1998: Upper ocean export of particulate organic carbon in the Arabian Sea derived from thorium-234. Deep-Sea Res. II, 45[10-11], 2461-2488.

Dickey, T., 1991: The emergence of concurrent high-resolution physical and bio-optical measurements in the upper ocean and their applications. Rev. of Geolys., 29[3], 383-413.

Dickey, T., J. Marra, M. Stramska, C. Langdon, T. Granata, R. Weller, A. Plueddemann and J. Yoder, 1994: Bio-optical and physical variability in the sub-arctic North Atlantic Ocean during the spring of 1989. J. Geophys. Res., 99[22], 541-551.

Dickey, T., J. Marra, R. Weller, D. Sigurdson, C. Langdon and C. Kinkade, 1998a: Time-series of bio-optical and physical properties in the Arabian Sea: October 1994-October 1995. Deep-Sea Res. II, 45[10-11], 2001-2025.

Dickey, T., D. Frye, H. Jannasch, E. Boyle, D. Manov, D. Sigurdson, J.D. McNeil, M. Stranska, A. Michaels, N. Nelson, D.A. Siegel, G. Chang, J. Wu and A. Knap, 1998b: Initial results from the Bermuda Testbed Mooring Program. Deep-Sea Res. I, 45, 771-794.

Dickey, T., D. Frye, J. McNeil, D. Manov, N. Nelson, D. Sigurdson, H. Jannasch, D. Siegel, A. Michaels and R. Johnson, 1998c: Upperocean temperature response to Hurricane Felix as measured by the Bermuda Testbed Mooring. Mon. Wea. Rev., 126, 1195-1201.

Dickey, T., S. Zedler, D. Frye, H. Jannasch, D. Manov, D. Sigurdson, J.D. McNeil, L. Dobeck, X. Yu, T. Gilboy, C. Bravo, S.C. Doney, D.A. Siegel and N. Nelson, 2001: Physical and biogeochemical variability from hours to years at the Bermuda Testbed Mooring site: June 1994-March 1998. Deep-Sea Res. II, 48[8,9], 2105-2131.

Foley, D.G., T.D. Dickey, M.J. McPhaden, R.R. Bidigare, M.R. Lewis, R.T. Barber, S.T. Lindley, C. Garside, D.V. Manov and J.D. McNeil, 1997: Longwaves and primary productivity variations in the equatorial Pacific at $0^{\circ}, 140^{\circ} \mathrm{W}$. Deep-Sea Res. II, 44[9-10], $1801-1826$

Griffiths, G., A. Knap and T. Dickey, 2000: Autosub experiment near Bermuda. Sea Tech., 41[2], 35-46.

Honjo, S. and R. Weller, 1997: Monsoon winds and carbon cycles in the Arabian Sea. Oceanus, 40[2], 24-28.

Lee, C.M., B.H. Jones, K.H. Brink and A.S. Fischer, 2000: The upperocean response to monsoonal forcing in the Arabian Sea: Seasonal and spatial variability, Deep-Sea Res. II, 47[7-8], 1177-1226.

Letelier, R.M., D.M. Karl, M.R. Abbott, P. Flament, M. Freilich, R. Lukas and T. Strub, 2000: Role of late winter mesoscale events in the biogeochemical variability of the upper water column of the North Pacific Subtropical Gyre. J. Geophys. Res., 105[28], 723-739.

McNeil, J.D., H.W. Jannasch, T. Dickey, D. McGillicuddy, M. Brzezinski and C.M. Sakamoto, 1999: Upper ocean response to the passage of a mesoscale eddy off Bermuda. J. Geophys. Res., 104[15], 537-548.

Tokar, J.M. and T. Dickey, 2000: Chemical sensor technology: current and future applications. In: Chemical Sensors in Oceanography, M.S. Varney, ed., Gordon and Breach Science Publishers, Amsterdam, 303-329

Valdes, J.R., K.O. Buesseler, and J.F. Price, 1997: A new way of catching the rain. Oceanus, 40[2], 33-35.

Varney, M.S., ed., 2000: Chemical Sensors in Oceanography. Gordon and Breach Science Publishers, Amsterdam, 333 pp. 